Año LXXXI. urtea $278-2020$

Septiembre-diciembre Iraila-abendua

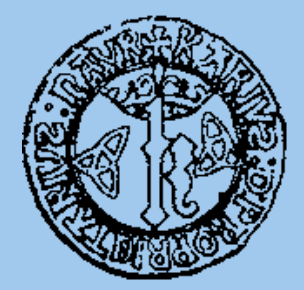

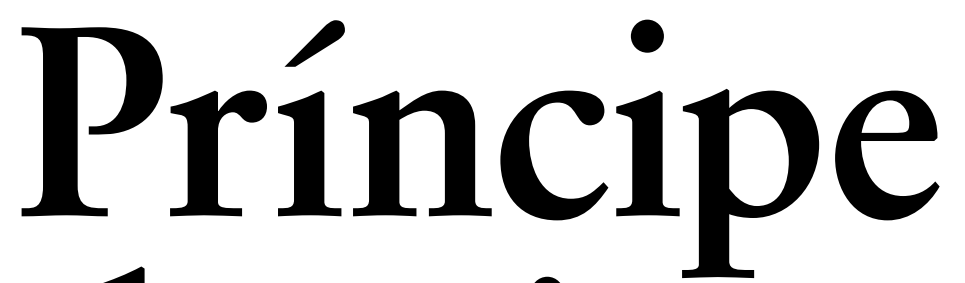
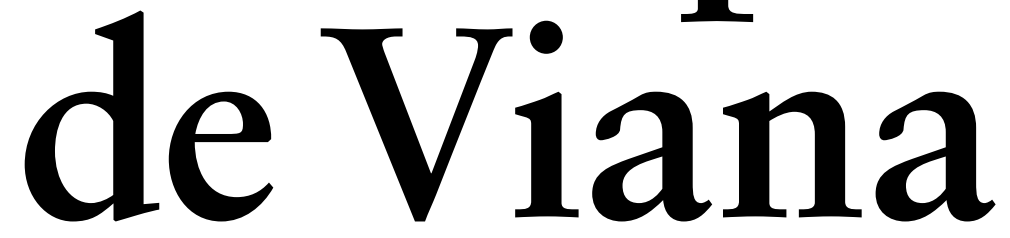

SEPARATA

Marisa Rey-Henningsen y el arte de la traducción de la literatura danesa

José Luis GARROSA GUDE 


\section{Sumario / Aurkibidea}

\section{Príncipe de Viana}

Año LXXXI - n. ${ }^{\circ} 278$ - septiembre-diciembre de 2020

LXXXI. urtea - 278. zk. - 2020ko iraila-abendua

\section{GUSTAV HENNINGSEN / MARISA REY-HENNINGSEN}

Homenaje / Omenaldia

Ignacio Panizo (coord./koord.)

Vol. I. lib.

Preámbulo / Hitzaurrea

Rebeca Esnaola Bermejo

Presentación / Aurkezpena

$\underline{\text { Ignacio Panizo Santos }}$

\section{TRAYECTORIA VITAL E INTELECTUAL DE GUSTAV HENNINGSEN \\ Y MARISA REY-HENNINGSEN / \\ GUSTAV HENNINGSENEN ETA MARISA REY-HENNINGSENEN \\ BIZITZA ETA IBILBIDE INTELEKTUALA}

Autobiografía de Gustav Henningsen

Autobibliografía de Gustav Henningsen

Bibliografía de Marisa Rey-Henningsen

Transcribiendo a Gustav y Marisa

Candela M. Camiño López

Gustav Henningsen, un encendido asombro ante la realidad

Mikel Azurmendi Inchausti

El danés peligroso. Semblante humano de Gustav Henningsen.

Evocación a cuatro manos

Jean Pierre Dedieu, Gunnar W. Knutsen

«Un danés peligroso» en los fondos del Archivo Histórico Nacional

Jaime Contreras Contreras 


\section{Sumario / Aurkibidea}

Gustav Henningsen: del antropólogo al historiador (pasando por archivero)

Juan Ignacio Pulido Serrano

Gustav Henningsen y Marisa Rey-Henningsen, folcloristas daneses en Galicia, 1965-1977 (entre magnetófonos y cuentos matriarcales)

José Manuel Pedrosa Bartolomé

Marisa Rey-Henningsen y el arte de la traducción de la literatura danesa José Luis Garrosa Gude

OBRA DISPERSA DE GUSTAV HENNINGSEN /

GUSTAV HENNINGSENEN OBRA BARREIATUA

Los documentos de Alonso de Salazar Frías. Una polémica sobre la brujería en España, 1610-1614

Gustav Henningsen

De la caza de brujas al culto de brujas

Gustav Henningsen

Archivos e historiografía de la Inquisición española

Gustav Henningsen

El síndrome de brujería infantil: el abuso infantil satánico contemporáneo

y los procesos por brujería infantil de antaño

Gustav Henningsen

999

La brujería y la Inquisición

Gustav Henningsen

Enciclopedia de la brujería

Gustav Henningsen

El vuelo de las brujas y los inquisidores españoles o cómo explicar lo imposible

Gustav Henningsen

Currículums

Analytic Summary

Normas para la presentación de originales / Idazlanak aurkezteko arauak /

Rules for the submission of originals 


\title{
Marisa Rey-Henningsen y el arte de la traducción de la literatura danesa
}

\author{
Marisa Rey-Henningsen eta literatura daniarra itzultzeko artea
}

Marisa Rey-Henningsen and the art of Danish literature translation

José Luis Garrosa Gude

IES José Hierro

garrosagude@yahoo.es

https://orcid.org/0000-0003-2440-2920

DOI: https://doi.org/10.35462/pv.278.11

Agradecemos la generosidad y la colaboración de Marisa Rey-Henningsen, de Gustav Henningsen y de su hijo Nils Jacob. También deseamos agradecer la atenta lectura y las valiosas correcciones y sugerencias que ha aportado José Manuel Pedrosa a este trabajo y la ayuda, a la hora de localizar textos, de Javier Espino Martín y de Blanca Ortiz Ostalé. 


\section{RESUMEN}

De entre las múltiples actividades de creación y de investigación de Marisa Rey-Henningsen (Madrid, 1936), destacamos sus traducciones de algunas importantes obras de la literatura danesa, hasta entonces inéditas en español. Gracias a su trabajo, el lector de lengua española ha podido acceder, entre otros, a textos de autores tan relevantes como En landsbydegns dagbog (Diario de un sacristán de pueblo), de Steen Steensen Blicher o I Spanien (Viaje por España), de Hans Christian Andersen. En este trabajo se aborda su labor como traductora y se hace hincapié tanto en su carácter pionero como en su importancia para el conocimiento de las culturas nórdicas.

Palabras clave: Steen Steensen Blicher; Hans Christian Andersen; literatura danesa; traducción; Marisa Rey-Henningsen.

\section{LABURPENA}

Marisa Rey-Henningsenek (Madril, 1936) egin zituen sormeneko eta ikerketako jarduera ugarien artean, literatura daniarreko obra handi -ordu arte gaztelaniaz argitaratu gabe zeuden- batzuen itzulpenak nabarmentzen dira. Haren lanari esker, gaztelaniazko irakurleak idazle garrantzitsuen testuak irakurtzeko aukera izan du; konparazio batera, Steen Steensen Blicher-en En landsbydegns dagbog (Herriko sakristau baten egunkaria) edo Hans Christian Andersenen I Spanien (Espainiako bidaia). Azterlan honetan, itzultzaile gisa egin zuen lana jorraturik, azpimarratzen da aitzindaria eta oso garrantzitsua izan zela literatura eskandinaviarraren ezagutza zabaltzeari begira.

Gako hitzak: Steen Steensen Blicher; Hans Christian Andersen; literatura daniarra; itzulpena; Marisa Rey-Henningsen.

\section{ABSTRACT}

Among the many creative and research activities of Marisa Rey-Henningsen (Madrid, 1936), we highlight her translations of some important works of Danish literature, previously unpublished in Spanish. Thanks to her work, Spanish language readers have been able to access texts by such important authors as En landsbydegns dagbog (Diario de un sacristán de pueblo), by Steen Steensen Blicher or I Spanien (Viaje por España), by Hans Christian Andersen. This paper studies her work as a translator and emphasises both her pioneering nature and her importance for the knowledge of Nordic cultures.

Keywords: Steen Steensen Blicher; Hans Christian Andersen; Danish literature; translation; Marisa Rey-Henningsen.

932 Príncipe de Viana (PV), 278, iraila-abendua, 2020, 931-943

ISSN: 0032-8472 | ISSN-e: 2530-5824 | ISSN-L: 0032-8472

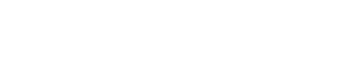


Un estudio exhaustivo de las creaciones y de la producción científica de Marisa Rey-Henningsen no se hallaría completo sin una referencia a su labor, importantísima y en muchas ocasiones pionera, como traductora al español de algunas obras relevantes de la literatura danesa.

La primera de esas traducciones fue la de En landsbydegns dagbog, una novelita de 1824 , tan desconocida hasta aquel momento para los lectores de lengua española como su propio autor, el poeta y narrador Steen Steensen Blicher (1782-1848). Diario de un sacristán de pueblo, que es el título en castellano, fue publicada en 1978 por el editor danés Poul Kristensen, y es una buena muestra de los rasgos principales que caracterizan la narrativa de aquel inclasificable escritor, un verdadero maestro en la ambientación de historias en los paisajes de su Jutlandia natal.

La propia traductora calificó este título como «una perla de la literatura danesa» en la dedicatoria que escribió en el ejemplar que iba a servir de obsequio a los reyes de España con motivo de su primera visita oficial a Dinamarca, allá por marzo de 1980. Se trataba, al parecer, de un libro con una hermosa encuadernación especial, en color verde, pero aún hoy se desconoce, como nos confesó Marisa Rey-Henningsen, si llegó o no a sus destinatarios.

La importancia de esta traducción del Diario de un sacristán de pueblo quedó confirmada pocos años después, ya que fue seleccionada para abrir el volumen dedicado a la novela escandinava del siglo XIX, en una antología que recogía otras cinco obras representativas de las literaturas danesa, sueca y noruega, y que formaba parte de la colección «Las mejores novelas de la literatura universal», que publicó la editorial Cupsa entre 1982 y 1984. 
Enrique Bernárdez, uno de los más reputados especialistas en las lenguas y las culturas nórdicas de la universidad española y él mismo un experto lingüista y un finísimo traductor, describía con estas palabras la traducción de la que estamos hablando:

Hemos reproducido aquí una hermosa traducción, debida a Marisa Rey-Henningsen, publicada recientemente en Dinamarca, en edición acompañada de introducción y comentarios, así como por dibujos. En pocas novelas como en esta se echan en falta, realmente, esas ilustraciones, para así transmitir, aunque solo en una pequeña parte, el ambiente en el cual creó Blicher y en el que se desenvuelven sus historias ${ }^{1}$.

Y no será esta la última vez que vea la luz la traducción que hizo Marisa Rey-Henningsen de El Diario de un sacristán de pueblo, pues volvió a publicarse en un libro que recogía una historia de la literatura danesa, desde sus remotos inicios en la Edad Media hasta las nuevas promociones de poetas y narradores de mediados del siglo XX. En el artículo titulado «Los libros que vienen», de la sección «Sábado Cultural» del diario $A B C$ del 27 de octubre de 1984, la periodista Pilar Trenas anunciaba la aparición de ese volumen y hacía este comentario:

Producto del intercambio cultural realizado entre España y Dinamarca es el volumen titulado Panorama de la literatura danesa, editado por Turner. En la antología que no es de reciente aparición, pero que conviene traer al presente, F. J. Billeskov Jansen se ha encargado de seleccionar los textos y de la introducción a los mismos, mientras que la traducción al español ha corrido a cargo de Marisa Rey, Berta Pallares, Pilar Lorenzo Tamm y Daniel Bohr, todos ellos hispanohablantes residentes en Dinamarca. Uffe Harder ha controlado las traducciones y el Ministerio de Cultura danés ha hecho posible la realización del proyecto con su ayuda económica (Trenas, 1984, p. 58).

En efecto, casi todas las traducciones corrieron a cargo de tres mujeres con fuertes vínculos familiares y culturales con Dinamarca. Marisa Rey-Henningsen se ocupó de verter a su idioma materno los títulos del periodo que va desde el Barroco hasta el siglo XX; aportó excelentes traducciones de textos de la condesa Leonora Cristina (1621-1698), Nicolaus Steno (1638-1686), Ludvig Holberg (1684-1754), Hans Christian Andersen (1805-1875), Søren Kierkegaard (1813-1855), Meïr Aron Goldschmidt (1819-1887), Georg Brandes (1842-1927), Jens Peter Jacobsen (1847-1885), Henrik Pontoppidan (1857-1943), Johannes V. Jensen (1873-1950), Martin Andersen Nexø (1869-1954), Jacob Paludan (1896-1975), Karen Blixen (1885-1962), H. C. Branner (1903-1966), Kaj Munk (1898-1944) y, claro está, el ya mencionado Steen Steensen Blicher (Billeskov \& Harder, 1984).

Pero, por alguna razón, de entre esta dilatada nómina de excelentes autores será de nuevo Blicher, con su sugerente combinación de tonos que van desde lo romántico has-

1 VV. AA. (1984, p. 6). En todas las citas unificamos los criterios tipográficos, corregimos las erratas evidentes y adaptamos la ortografía a las reglas ortográficas actuales. 
ta lo realista, quien aparezca en las diferentes investigaciones de profesores y autores españoles que hemos podido documentar.

Así, la traducción de Marisa Rey-Henningsen incorporada al Panorama de la literatura danesa sirvió a Javier Espino Martín, en la actualidad docente en la Universidad Nacional Autónoma de México y especialista en gramática latina y en recepción de la Antigüedad clásica, para presentar la comunicación «La frustración de amor en $E l$ diario de un sacristán de pueblo de Steen Steensen Blicher y sus referentes más inmediatos», con ocasión del Congreso Internacional «Amor y Erotismo en la Literatura», que se celebró en Salamanca en 1998. El profesor Espino analizaba los símbolos amorosos rastreables en el relato de Blicher y los ponía en relación con otros análogos insertos en el Werther de Goethe y en los Cantos de Giacomo Leopardi (Espino, 1999, pp. 305-311).

Pero, a pesar de sus valores intrínsecos y de la valoración altamente positiva de tantos expertos, no todos los lectores españoles que accedieron al texto de Blicher traducido por Marisa Rey-Henningsen quedaron igual de satisfechos. O al menos eso se desprende de unas líneas escritas por el poeta, profesor y traductor Luis Alberto de Cuenca. El también crítico literario reseñaba la traducción de otra magnífica novelita del escritor de Jutlandia, El párroco de Vejlby, debida a Blanca Ortiz Ostalé ${ }^{2}$, probablemente la mejor traductora del danés al español en la actualidad, artífice de una extensa relación de obras que incluso le han merecido el reconocimiento expreso de las autoridades danesas, como prueba el que le fuera concedido en 2008 el Premio Danés de Traducción; Cuenca aludía al Diario de un sacristán de pueblo con estas palabras:

En 1984, Ediciones Turner publicó un libro de más de 600 páginas titulado Panorama de la literatura danesa. Iba firmado por F. J. Billeskov Jansen y Uffe Harder como antólogos, y cubría, en edición bilingüe danés-castellano, toda la andadura cronológica de la literatura de Dinamarca, desde la Edad Media hasta los años 60 del siglo XX. En ese libro conocí yo la existencia de Steen Steensen Blicher (17821848), el creador de la novela danesa moderna. Alguien que «se inspiró en las tradiciones folklóricas orales y escritas para transformar acontecimientos más o menos reales en narraciones de gran vigor poético», como rezaba la nota introductoria a la pieza narrativa de Blicher presente en el citado florilegio, que no era otra que Diario de un sacristán de pueblo y que debo confesarles que me pareció un auténtico pestiño.

Por eso, y acordándome con horror de aquella aburridísima muestra del supuesto talento del escritor danés, no presté de entrada el menor interés por la nouvelle que Blanca Ortiz Ostalé y Ardicia Editorial acababan de colocar en los escaparates de las librerías españolas y que llevaba el título de El párroco de Vejlby (1829). Craso error por mi parte que pude solventar hojeando las páginas del prólogo de la traductora

2 El párroco de Vejlby (Prcesten i Vejlbye, 1829) figura en el Canon Cultural Danés elaborado por el Ministerio de Cultura de aquel país, y se considera el primer relato policiaco de la historia. Aparte de la excelente edición que mencionamos, publicada por la editorial Ardicia en 2018, existe también una traducción al gallego, de 2019, en la editorial Hugin e Munin, que no hemos podido consultar. 
y dándome cuenta al instante de la gran diferencia que había entre aquel rollo del sacristán rural y esta delicia paleodetectivesca. De un hijo de un pastor protestante de la luterana Dinamarca y de una madre con serios problemas mentales podía y debía esperarse mucho más que aquel dietario sacristanesco. Y así fue (Cuenca, 2018, p. 10).

Como puede observarse en la crítica (que no reproducimos en su integridad) el escritor madrileño no ahorró calificativos a la hora de describir el grado de aburrimiento que le produjo el Diario de un sacristán de pueblo y de contraponerlo al placer que experimentó con la lectura de El párroco de Vejlby. Pese a su sesgo muy subjetivo, esta divergencia de gustos muestra bien a las claras la variedad de tonos que conviven en la obra de Blicher y nos hace agradecer aún más a sus traductoras el trabajo que se tomaron para que el público de lengua española pudiera conocer, aunque fuera solo en una mínima parte, el universo narrativo de un autor al que sus compatriotas sitúan a la par, nada menos, de la figura gigantesca de Hans Christian Andersen.

Y precisamente de Andersen es la traducción más célebre de Marisa Rey-Henningsen, la del Viaje por España (1989), que además venía a cubrir un hueco importante en el catálogo de sus obras disponibles en lengua española. Aunque la calidad literaria de este libro no está a la misma altura que la de otras de sus muchas creaciones, se trata de un título clave para entender el interés y la admiración que siempre demostró Andersen por nuestro país y para conocer, sobre todo, el tremendo impacto que le supuso encontrarse con una realidad más bien hostil y con la indiferencia y el desconocimiento que por su obra manifestaron nuestros compatriotas.

Los especialistas en literatura danesa y en las relaciones culturales entre España y Dinamarca ya venían advirtiendo de esta laguna desde muchos años antes de que se publicase esta traducción. El 27 de marzo de 1955 apareció en el diario $A B C$ un largo artículo titulado «Hans Christian Andersen y España», que firmaba J. O. Kock, y del que extractamos algunas interesantes consideraciones:

Durante toda su vida Andersen sintió un amor desgraciado por el teatro y llegó a escribir un par de obras teatrales con sujetos españoles: la batalla de las Navas de Tolosa y la estancia de las tropas españolas en Dinamarca, 1808, al mando del marqués de La Romana, pero no es posible asegurar que estas dos piezas le procurasen muchos admiradores en España. Es de creer, por el contrario, que su libro de viajes por España tendría interés para el lector español, pero, al parecer, nunca ha sido traducido al castellano.

Andersen fue un viajero incansable, y sus libros de viajes son de lo mejor que existe en la literatura danesa. En su juventud, era Italia el país preferido por los escandinavos que querían visitar latitudes más meridionales, y Andersen siguió la costumbre de sus compatriotas. A pesar de ello, pensó repetidamente en visitar España, pero siempre tropezó con uno u otro obstáculo, hasta que logró realizar su propósito cuando ya cifraba en los sesenta, en el año 1862, siendo el resultado un tomito que lleva por título En España, que sin ser su mejor libro de viajes es la mejor descripción que de España existe en la literatura danesa. 
Muchas son las causas de que este libro no llegue a la altura de las descripciones de viajes escritas en su juventud. En primer lugar, era ya demasiado anciano para poder estudiar, con fruto, la lengua y la cultura españolas y, además, al hacer su viaje era un hombre famoso que viajaba con sendas cartas de introducción y al que prestaban en todo momento ayuda los cónsules daneses y otros compatriotas residentes en el extranjero. A causa de ello no llegó a entrar en contacto con el hombre del pueblo, y la descripción de este viaje tiene, en consecuencia, algún parecido con una película muda. Pero, a pesar de todo, este libro contiene detalles deliciosos: Andersen tenía buen ojo para apreciar las peculiaridades del ambiente que le rodeaba y, asimismo, poseía grandes dotes de narrador para relatar por escrito las impresiones recibidas. Así, algunos puntos del libro, como un chaparrón en Barcelona y sus viajes en diligencia, están trazados de forma inmejorable (Kock, 1955, pp. 8-9).

Kock concluye su artículo con una valoración global del libro y con la expresión de un deseo que, como ya sabemos, iba a tardar algunas décadas en verse cumplido:

«Si se desea ser original como autor de viajes, uno debe decir tan solo la verdad», escribe Andersen en uno u otro lugar, y desde este punto de vista hay que reconocer que el libro de Andersen es más original que la mayoría de libros sobre España escritos por los autores románticos del norte de Europa, pudiéndosele perdonar, por esta causa, que el estilo en que el libro está escrito sea más prosaico que lo corriente en aquellos tiempos.

En Dinamarca nos preparamos ahora para celebrar el CL aniversario del nacimiento de Andersen, el 2 de abril de 1805, y nuestro mayor deseo en esta ocasión es que nuestro escritor reciba, en todos los países del mundo, muestras del aprecio que merece. Por lo que respecta a los países de lengua española, la mejor manera de expresar este aprecio sería acometer una edición de sus cuentos, a través de una buena traducción, y que se sacase su libro de viajes por España del olvido y de la ignorancia de que es objeto (Kock, 1955, p. 9).

Algo más de un cuarto de siglo después, en 1981, de nuevo en el periódico $A B C$, aparece una página dedicada a Andersen con un significativo recordatorio inicial en el que se recuerda que este libro estaba todavía por traducir al castellano; y ya en el texto del artículo, se aventuran algunas razones que pudieran estar detrás de esta inexplicable carencia:

Cuando ya era escritor famoso, Andersen decidió hacer ese viaje a Portugal, invitado por amigos y conocer España, cuyo exotismo, folklorismo y romanticismo comenzaba a perfilarse en la Europa del XIX. En 1862 tuvo lugar el viaje, Andersen escribió cartas al ministro plenipotenciario danés en Madrid y a una persona recomendada de la capital de España, comunicándoles que iba a pasar por Madrid.

El escritor danés, confiado en su fama, espera que se le reciba con todos los honores que le corresponden, pero no ocurrió así. El vacío fue de lo más absoluto. No estaban en Madrid ni el ministro plenipotenciario, ni la persona recomendada. El diplomático danés estaba de vacaciones. El desencanto de Andersen no pudo ser mayor, y esto se dejó traslucir en su libro. 
Para Andersen, España es un país sucio y lleno de moscas, y Madrid una ciudad polvorienta e insoportable, donde el desorden y las mulas con carros molestan por doquier. No tuvo suerte el escritor en su viaje por España, la diligencia se le atascó al vadear un río; la abrupta geografía de nuestro país le produjo un viaje incómodo, nervioso y, para el colmo, sin acogida alguna en Madrid, lo que colmó su ira y malhumor.

Seguramente no hubo mala voluntad por parte de Andersen al escribir sobre España. Lo pasó mal y lo cuenta tal y como le ocurrió. «En España es un libro muy subjetivo en ese aspecto», dice Jesús Riosalido, escritor y diplomático durante varios años en Copenhague, que está traduciendo los cuentos de Andersen en una edición completa.

El libro En España no se ha traducido al castellano todavía, quizá por esa negatividad de Andersen al enjuiciar nuestro país. Actualmente, en una buena impresión ilustrada danesa, el libro se expone en la vitrina especial que el Instituto Nacional del Libro (INLE) ha dedicado al escritor danés, con motivo de su CLXXV Aniversario (Sáez-Angulo, 1981, p. 34).

Por fortuna, poco tiempo después la prensa pudo ya anunciar la aparición de tan esperado libro y, como puede verse en esta reseña de Ana Salado, también para $A B C$, que transcribimos en su totalidad por su elevado interés, destacó la compleja atracción que experimentaba Andersen por España desde mucho antes de pisar sus tierras, de conocer a sus gentes y de ser víctima del consiguiente e inevitable desencanto:

A Hans Christian Andersen le fascinaba España. O, al menos, le fascinó hasta que viajó por ella. A Andersen debía pasarle eso con la mayoría de sus experiencias, aunque él nunca lo hubiera reconocido expresamente. Prefería seguir viviendo el cuento de su vida y hasta tituló de ese modo, El cuento de mi vida, su obra autobiográfica, ya publicada en España, y reseñada en estas mismas páginas.

La capacidad del escritor danés para ver las cosas de la manera en que debían ocurrirle, y no de otra, la pone de relieve muy acertadamente la traductora al español de dicho libro, Pilar Lorenzo, advirtiendo al lector que no es oro todo lo que reluce en la vida de Andersen.

Y hubiera sido imposible, porque fíjense qué joya: «Mi vida es un bello cuento, tan rica y dichosa. Si de niño, cuando salí a recorrer el mundo, solo y pobre, me hubiera salido al paso un hada prodigiosa que me hubiera dicho: Escoge tu camino y tu meta, que yo te protegeré y te guiaré... no pudiera mi suerte haber sido más feliz». Lo que caracteriza a Hans Christian Andersen es su inmensa capacidad para la fábula.

Pero, como decíamos, a este espléndido cuentista le fascinaba España. El origen de tan romántica atracción se encuentra en su más tierna infancia, cuando, a la edad de tres años, un soldadito español -de un regimiento que andaba por allí colaborando en correrías napoleónicas- lo alzó y apretó en sus brazos. Desde entonces, Andersen empezó a buscar ese sur de ojos negros, nobleza y pasión que pensaba España.

Y España empezó a aparecer en su obra y a convertirse en el objetivo soñado de sus viajes. Al fin, en 1862 -Andersen contaba cincuenta y siete años-, el sueño se hizo realidad y nuestro escritor llevó a cabo la visita a España, de cuatro meses de duración, cuyas peripecias e impresiones se relatan en nuestro libro de hoy. 
Andersen nos presenta un viaje instructivo, bastante placentero a pesar de las diligencias y de ciertos alojamientos, lleno de mujeres y de lugares bellos y de cónsules del norte cuyos salones se abren a Andersen a la par que sus corazones. Como nuestro admirado fabulador no hablaba la lengua del país y, por tanto, no le era fácil hacer amistad con los españoles, lo antes dicho no era poco.

Y hay que reconocer además que, ante las tribulaciones propias de todo viaje a territorios subdesarrollados, Andersen muestra el talante del más valiente y sufrido expedicionario.

Tan solo deja traslucir cansancio y tristeza en Madrid. En Madrid, Andersen, todo un chicarrón del norte, pasó más frío que en ninguno de sus inviernos daneses. Los amigos de sus amigos no estaban en casa y en la Plaza Mayor se sintió «oprimido como en el patio de una cárcel».

Para colmo de los colmos, en Madrid nadie conocía su obra y los escritores no le hacían caso. Claro que él no lo cuenta exactamente así, pero la autora de esta bien realizada edición, Marisa Rey, demuestra con otros textos lo que ya al simple lector le parece adivinar: que tal vez la fascinación de Andersen por España murió en España (Salado, 1990, p. 54).

Marisa Rey-Henningsen no se limitó a ofrecernos una escueta versión en español del libro original, sino que lo acompañó de un prefacio, en el que desgranó algunos datos relativos a la génesis del relato y explicó sus criterios de edición, y lo cerró con un epílogo, que por su alcance y extensión podríamos considerar, con toda justicia, un original y comprometido ensayo. Este epílogo, titulado «Hans Christian Andersen: su obra literaria y su tradición cultural», explora los orígenes del amor por España del escritor de Odense y aporta valiosísimos apuntes sacados de su diario, con lo que contribuye a que se conozca mejor tanto el contenido del volumen como el laborioso proceso de documentación que acompañó a su redacción final. Especial importancia reviste también el análisis de la complejísima personalidad de Andersen y de la ideología subyacente a sus relatos, profundamente influida por los presupuestos morales y teológicos del protestantismo, como muy bien explica Marisa Rey-Henningsen:

El ardor narrativo, la fuerza descriptiva, la vehemente acusación de los poderosos y encumbrados, las amargas vivencias que dejaron huella en su vida particular, condicionan el estilo de Andersen: irónico, casi mordaz, de un sentimentalismo que hoy consideramos excesivo, a veces de una crueldad dramática angustiosa, pero acertada. Él despreciaba a los arribistas y a los parásitos aduladores, y a todos aquellos que, sin más mérito que el de haber nacido en buena cuna, influían en los destinos de espíritus de mucha más valía. Poseía una visión del mundo cruda y realista, a la que oponía su profunda fe religiosa y su esperanza en la justicia divina y en el triunfo final de la bondad y de la verdad, aunque esto último con frecuencia solamente lo hallemos implícito en sus relatos. Es cierto que su obra está poblada de «madres abnegadas hasta más allá de los límites de la naturaleza, criaturas abismadas en una resignación aberrante», que a los españoles, mentalizados por una tradición católica, adaptada al temperamento propio, nos podrán parecer «toscos remedos de virtudes cristianas» y «una soterrada hipocresía». Pero este juicio emitido por Ana María Matute en su introducción a La sombra y otros cuentos, de 
Hans Christian Andersen, no es justo. Los personajes y los hechos de los cuentos de Andersen, como los de sus novelas y poemas, hay que interpretarlos a la luz de una tradición protestante, impregnada de un sentido de Dios justiciero, de acuerdo con un concepto de la vida y de los seres humanos como algo sometido a una justicia universal. De acuerdo con esta visión justiciera de la vida, en el mundo creado existe un equilibrio, que para ser mantenido exige que todo pecado sea expiado en este mundo, y que hasta los mayores placeres sean pagados con sufrimientos proporcionales, sin que nada pueda cambiar la sentencia divina, condicionada tan solo por la infinita misericordia de Dios y el sacrificio de la Cruz, y no por méritos personales o por la penitencia de cada uno como presupone la doctrina católica. Tan solo la muerte libera al protestante de la carga abrumadora de los pecados cometidos, carga que únicamente una fe recia en la misericordia divina puede hacer llevadera. Esta conciencia protestante de irreparable imperfección o de perenne falta de gracia entra en conflicto con los ideales de perfección y grandeza moral, representados por los dioses de la antigua mitología nórdica, y que siguen formando parte de la mentalidad escandinava. El dilema del hombre que lleva dentro de sí la ambición de ser perfecto, pero que se cree hasta la muerte «imperfecto», ha condicionado el carácter y la mentalidad norteeuropeos y ha quedado ampliamente reflejado en la literatura, y en el comportamiento sociocultural de estos pueblos. Quizá sea esta la razón principal por la que los hermanos protestantes, anglosajones y germanos, se identificasen tan pronto con los personajes de Andersen y comprendiesen tan admirablemente la «filosofía» anderseniana. Y por esta misma razón, el pensamiento de Andersen tardaría en cuajar entre un pueblo católico, felizmente influido por la idea optimista de la redención y del perdón de los pecados y la esperanza del premio a las buenas obras ${ }^{3}$.

La extensa cita se justifica para que se entiendan mejor las implicaciones culturales de una obra que ha sido regularmente mal leída y aún peor comprendida y que sirve, además, para adentrarse en los intrincados vericuetos psicológicos de una personalidad como la de Andersen, siempre ansiosa de un reconocimiento social que, por supuesto, no logró en España.

El ya mencionado Enrique Bernárdez, que une a sus profundos conocimientos de las culturas nórdicas la experiencia de haber traducido tanto los cuentos completos de Andersen como su novela de ambiente italiano El improvisador (1835), al hablar de sus libros de viajes, recomienda la edición que estamos comentando con estas palabras:

Sobre el libro En España, recomendamos al lector la lectura de la traducción y el epílogo de Marisa Rey, en Alianza Editorial (1988). Veremos allí cuál fue el choque al comprobar que las cosas no eran ya como en otros tiempos, aunque España seguía muy anclada en el pasado en demasiadas cosas poco románticas, lo que incluía la in-

3 Andersen (1988/1995, pp. 255-256). Marisa Rey-Henningsen se refiere al prólogo que escribió Ana María Matute para La sombra y otros cuentos, la antología de cuentos de Andersen que tradujo Alberto Adell para la editorial Alianza. 
comodidad de los transportes y los hoteles. Se siente decepcionado cuando, al cruzar Sierra Morena, le indican que ya no hay bandoleros, y se molesta porque los intelectuales españoles no sabían prácticamente nada de él. Marisa Rey rastreó la prensa española de la época y comprobó que en ningún momento se hizo referencia alguna a la presencia del que, en otras partes de Europa, era ya un escritor muy conocido y respetado. Claro que Andersen tenía ideas un tanto erróneas sobre España; así, se asombra del frío invernal de Madrid y de que ya no era la ciudad de la españolidad tópica, como explica en un poema (en la traducción de M. Rey, p. 201):

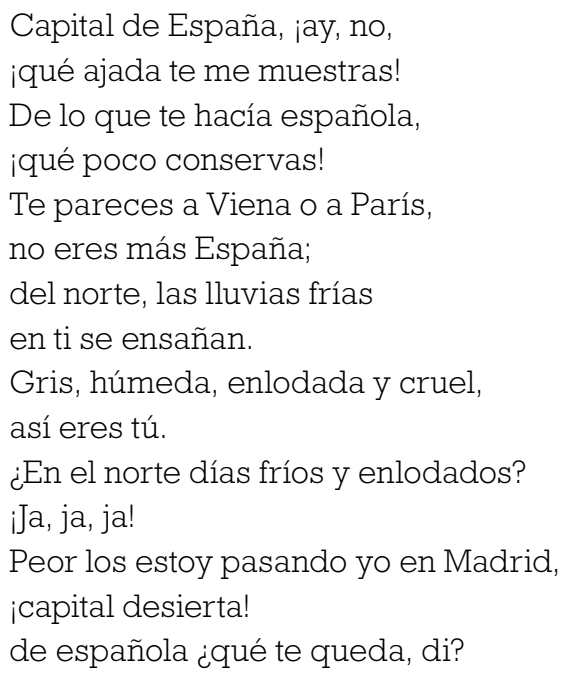

Huyendo del frío de Madrid, Andersen escapa... a Burgos. De donde tiene que huir a toda prisa antes de que la nieve deje bloqueados los caminos (Andersen, 2015, p. 70).

Nadie mejor que una mujer como Marisa Rey-Henningsen, con una vida y una obra a caballo entre dos naciones y entre dos maneras de pensar y de sentir, tantas veces antagónicas, para analizar e interpretar los sentimientos de un danés solitario y errabundo en aquella España que para el viajero constituyó un enigma.

La traducción del Viaje por España vino a llenar un hueco y a saldar (y lo hizo con creces, como hemos visto) la deuda que en España teníamos contraída con Andersen; el trabajo de Rey-Henningsen es innegable que representó un hito muy importante en la historia de la recepción y de la interpretación del conjunto de su obra en nuestro país, y despejó el camino para que muchos le pudiésemos considerar en una faceta que trascendía la de simple escritor de cuentos infantiles, que era la única que se le reconocía.

El mérito de los trabajos de traducción de Rey-Henningsen es tanto mayor cuanto que la autora hispano-danesa hubo de compatibilizarlos con el sacar adelante una familia de cuatro hijos; con su ayuda y su colaboración, sumamente generosa y comprometida, en todas las empresas intelectuales que emprendió su esposo Gustav, ya 
que tradujo sus estudios, entre los que destaca su traducción al español de El abogado de las brujas. Brujería vasca e Inquisición española (a partir de The Witches' Advocate. Basque Witchcraft and the Spanish Inquisition (1609-1614), de 1980, y Heksenes advokat. Historiens største hekseproces, de 1981, que se publicó en 1983 y, de nuevo, en 2010, como «nueva edición actualizada»); con sus trabajos más o menos mercenarios o burocráticos de traducción, pues trabajó para muchas empresas que contrataron sus servicios de traductora e intérprete (así, cuando se instaló en Copenhague en 1957 trabajó, como traductora, para una empresa danesa de reaseguros); con su faceta de creadora de ficción en danés, que se plasmó en la publicación de Prinsessen og dyrene [La princesa y los animales] (1979) y Djeevelens skygge [La sombra del diablo] (1980); y con el desarrollo de su propia e importantísima obra ensayística y académica, que se concretó en libros como Plovkvinden. Eventyr og skæmtehistorier fra Galicia [La aradora: cuentos y anécdotas de Galicia] (1977), Den frugtsommelige abbedisse: Kvinder og magt $i$ middelalderen [La abadesa encinta: mujer y poder en la Edad Media] (1983) y, sobre todo, en su tesis doctoral, que fue publicada en dos volúmenes en inglés: The World of the Ploughwoman: Folklore and Reality in Matriarchal Northwest Spain (1994) y The Tales of the Ploughwoman. Appendix to FFC 254 (1996). Su firma se halla también en una interesantísima serie de artículos de investigación sobre el folclore danés y sobre el folclore gallego. Si lo subrayamos es porque la cualificación como etnógrafa de Marisa Rey-Henningsen sirve para explicar la calidad de sus traducciones al español de obras danesas que tenían mucho que ver, siempre, con la cultura popular.

Sirvan estas pocas líneas de sencillo homenaje a una mujer que, con su entusiasmo y su esfuerzo personal sostenidos, tanto ha contribuido a estrechar las relaciones culturales entre Dinamarca y España y a profundizar en su conocimiento recíproco.

Queda mucho por hacer para dilucidar la importancia de la contribución de diversos traductores y profesores en esa apasionante tarea del reforzamiento del conocimiento entre ambos países; pero algo sobre lo que nadie alberga dudas es que la precursora fue Marisa Rey-Henningsen; su impulso fue absolutamente decisivo para dar a conocer al gran público de lengua española algunos de los aspectos más interesantes de una literatura, la danesa, tan desconocida en aquel momento como desvirtuada por falsos tópicos y por lecturas deficientes.

\section{LISTA DE REFERENCIAS}

Andersen, H. C. (2015) Cuentos completos (6. ${ }^{\mathrm{a}}$ ed.) (ed., introd. y notas E. Bernárdez). Madrid: Cátedra.

Andersen, H. C. (1988/1995). Viaje por España (1. ${ }^{a}$ ed., 1. ${ }^{a}$ reimp.) (trad. y epílogo M. Rey). Madrid: Alianza.

Billeskov Jansen, F. J. \& Harder, U. (1984). Panorama de la literatura danesa. Madrid: Turner.

Cuenca, L. A. de. (2018). Arqueología detectivesca. ABC Cultural, 13-10-2018, 10. 
Espino Martín, J. (1999). La frustración de amor en El diario de un sacristán de pueblo de Steen Steensen Blicher y sus referentes más inmediatos. En V. González Martín (ed.), Amor y erotismo en la literatura (pp. 305-311). Salamanca: Caja Duero.

Kock, J. O. (1955). Hans Christian Andersen. ABC, 27-03-1955, 8-9.

Sáez-Angulo, J. (1981). Hans Christian Andersen, autor de ciento cincuenta cuentos para niños. $A B C, 06-01-1981,34$.

Salado, A. (1990). Viaje por España (Hans Christian Andersen). ABC, 27/01/1990, 54.

Trenas, P. (1984). Los libros que vienen. ABC, 27/10/1984, 58.

VV. AA. (1984). La novela escandinava en el siglo XIX (introd. Enrique Bernárdez) (Las mejores novelas de la literatura universal, XX). Madrid: Cupsa. 
0 